\title{
Diagnosis and Management of Ectopic Solid Cervical Thymus and Cervical Thymic Cyst in children: Case report and systematic review of the literature
}

\author{
Annette Chang ${ }^{1}$, Ramesh Nataraja ${ }^{2}$, Eduard Pudel ${ }^{1}$, Robert Stunden ${ }^{1}$, Stephen Bare ${ }^{1}$, \\ and Maurizio Pacilli ${ }^{2}$ \\ ${ }^{1}$ Monash Health \\ ${ }^{2}$ Monash University
}

April 28, 2020

\begin{abstract}
Background: We aimed to clarify the surgical management of ectopic cervical thymus (ECT) in children. Methods: Case report and systematic review of the literature. Results: We report a case of ECT in a 10-year old girl initially misdiagnosed as branchial cyst. A systematic review of the literature (1997-2018) identified 143 paediatric patients (150 ECT) diagnosed as follows: 10 incidentally at autopsy, 107 after complete surgical excision, 33 after needle/ incisional biopsy/ imaging only. There were no reports of malignancy. Conclusions: ECT is a benign and relatively rare condition in children. ECT can be the only active thymus and careful consideration should be taken prior to its excision in young children. We recommend that ECT should be considered in the differential diagnosis of lateral neck masses in children. In cases where the exact aetiology is unclear investigation with an MRI scan of neck and thorax to avoid inappropriate surgical intervention.
\end{abstract}

\section{BACKGROUND}

The thymus originates around 6 weeks of gestation from the paired third pharyngeal pouches together with the inferior parathyroid glands. ${ }^{1}$ Fusion of the bilateral primordial thymus occurs around the $8^{\text {th }}$ week of gestation. The thymus then migrates caudally along the line of embryological descent to enter into the anterior mediastinum. Ectopic cervical thymus (ECT) is a rare lesion caused by the abnormal descent of the thymus gland into the mediastinum and represents less than $1 \%$ of neck lesions in children. ${ }^{2}$ The lesion can be solid, partially or predominantly cystic, with the latter accounting for majority (76-92\%) of cases. ${ }^{3}$ The presentation is generally with an asymptomatic lateral neck lump. Symptoms can occur as a result of infection, airway obstruction or, in neonates and infants, feeding difficulties in large ECT. ${ }^{4-9}$ The diagnosis can be suspected with ultrasound scan (USS). ${ }^{10-12}$ However, magnetic resonance imaging (MRI) has the added benefits of clarifying the anatomy, especially the relation with neck vascular structures, documenting additional ectopic thymic tissue in the neck and the presence of a normal mediastinal thymus. ${ }^{13}$ Fine needle aspiration cytology (FNAC) may also be helpful in the diagnosis although might not always be accurate. ${ }^{14-16}$ Surgical excision might be indicated in large symptomatic masses. Nevertheless, in children, conservative management might be appropriate in asymptomatic cases and in the absence of a normal mediastinal thymus; this is to prevent rendering a child athymic and subsequently immuno-incompetent. ${ }^{9,} 17,18$ We herein describe a case report of a 10-year old girl with a right neck ECT which was initially misdiagnosed as branchial cyst. We also performed a systematic review of the paediatric literature in the last 20 years. We aim to clarify the management of ECT in children.

\section{METHODS}


We report a case of ECT in a 10-year old child and performed a systematic review of the English literature published between January 1997 and June 2019. We searched the following scientific databases: PubMed, ScienceDirect, Clinical Trials, The Cochrane Library, Database of Abstracts of Reviews of Effectiveness, IngentaConnect, OvidMedline, Turning Research Into Practice (TRIP) database. We used a combination of search terms: "cervical ectopic thymus"; "cervical ectopic thymic tissue"; "cervical thymic cyst".

Selected studies included: case reports and retrospective/prospective case-series limited to paediatric population (0-18 years of age). We excluded publications documenting ectopic thymic tissue present within the thyroid gland, incidental findings on pathology specimens during neck procedures such as thyroidectomy and unclear/mixed diagnosis. A full text copy of each article was obtained for detailed review. References within the included articles were screened to identify additional relevant articles. The full text of the potentially eligible studies was obtained and assessed for eligibility by two reviewers (AC and MP). The data were recorded in a database (Microsoft Excel 2016, Microsoft Corporation). Data are reported as number of cases $(\%)$, median and (range), mean \pm SD. The Kruskal-Wallis $\mathrm{U}$ test was used to identify differences between the groups. $\mathrm{P}$ values $<0.05$ were considered significant.

\section{CASE REPORT}

A 10-year old girl presented with a palpable right neck lump. This was described as a slow-growing lesion which would intermittently resolve. On examination a $3 \times 2 \mathrm{~cm}$ solid, mobile, non-painful lesion was palpated deep to the anterior border of the sternocleidomastoid muscle. The rest of the clinical examination was unremarkable. An ultrasound scan (USS) reported a cystic mass $4.2 \times 4.0 \times 3.8 \mathrm{~cm}$ in diameter with mobile internal echoes and a diagnosis of a branchial cleft cyst was made (Figure 1A). An excision via a transverse incision was attempted under general anaesthesia by a general paediatric surgeon: due to unclear diagnosis and dense adhesion to neck neurovascular structures, the procedure was abandoned; an incisional biopsy was therefore obtained, and histology documented xanthogranulomatous inflammatory change and fibrosis. A post-operative magnetic resonance imaging (MRI) scan documented a soft tissue lesion with cystic/fluid components at the right parapharyngeal space extending to the retropharyngeal space (Figure 1B); it also confirmed the presence of normal mediastinal thymus. The patient returned to theatre for formal excision one month later as a joint procedure by the general paediatric surgeon and an ear nose and throat (ENT) surgeon. A mixed cystic/solid mass was found posterior to the sternocleidomastoid muscle, adherent to the carotid artery and internal jugular vein (IJV) and adjacent to the trachea. The ansa cervicalis which was densely adherent to the lesion, was identified with a nerve stimulator and preserved. The lesion was then completely excised with no significant complications. Histological analysis revealed an ECT (Figure 1C). The patient remains well at 18 months follow-up with no evidence of recurrence.

\section{SYSTEMATIC REVIEW OF THE LITERATURE}

A total of 1334 titles and abstracts were identified from searching the scientific databases (Figure 2). After the removal of duplicates, a total of 313 full-text journal articles were retrieved. Of these, 71 contained adequate data on ECT in children and were therefore included in the final review. ${ }^{4-8,10-13,15-76}$ These included both case series and case reports. A total of 192 (unilateral and bilateral) cases of ECT reported in children were identified. 42 cases ( 4 studies $^{2}, 9,14,77$ ) were excluded because of insufficient data resulting in 150 cases ( 7 bilateral) in a total of 143 patients (Figure 3). We classified cases according the surgical management and pathology as: ECT identified at autopsy, conservatively managed solid and cystic ECT, surgically excised solid ECT and surgically excised cystic ECT. Some manuscripts reported more than one type of ECT. ${ }^{12,18,34,51,68}$

\section{ECT identified at autopsy}

Kotani et al reported 7 cases (3 bilateral) of ECT found on autopsy (Table 1) ${ }^{44}$. In one case the cause of death was attributed to mechanical asphyxia secondary to bilateral ECT (case 6). All patients were found to have normal mediastinal thymus.

\section{Conservatively managed solid and cystic ECT}


We identified 33 cases (30 patients, 3 bilateral) with a diagnosis of a solid ECT which were conservatively managed (Table 2). ${ }^{8}, 10-13,16,47,48,50,52,56,65,71,72,76$ We did not identify any cases of conservatively managed cystic ECT.

The majority $(75 \%)$ of lesions were found in the neck. More than one modality of imaging was performed in $8(26 \%)$ patients; a CT scan was not performed in any patient. Diagnosis on imaging only was made in $23(76 \%)$ while 7 patients required a biopsy to confirm the diagnosis. Of these, 2 patients were initially misdiagnosed on imaging (1 vascular anomaly and 1 lymphoblastic lymphoma).

One patient who was diagnosed with ECT on USS and initially managed conservatively required subsequent surgical excision due to an increase in size and the onset of respiratory symptoms. ${ }^{12}$ There were no other complications of patients managed conservatively, follow-up was reported in 8 patients only. Normal mediastinal thymus was present in 11 patients and absent in 1 patient: no information was available in 18 patients.

\section{Surgically excised solid ECT}

We identified 28 cases (28 patients) of surgically excised solid ECT (Table 3). ${ }^{7}, 12,15,18,19,29,34,37,38,41,43,45,46,51,53,54,58$,

The majority $(64 \%)$ of these lesions were found in the neck. More than one modality of imaging was performed in 17 (60\%). Pre-operative diagnosis was reported for 18 cases and none of these included an ECT as a possible alternative. Pre-operative diagnoses included: neuroblastoma, lymphatic malformation, teratoma, branchial remnant, dermoid cyst, hamartoma, haemangioma, lymphadenopathy, rabdomyosarcoma, leukemia. Seven patients underwent a FNAC/biopsy before definitive excision: diagnosis was ECT in 2 cases, inconclusive in 2 cases and incorrect in 3 cases (1 lypoblastoma, 1 chronic inflammatory process, 1 lymphoma). One child required revisional surgery to completely excise the persistent neck mass, in which an incisional biopsy had initially diagnosed as a chronic inflammatory mass. ${ }^{15}$ Normal mediastinal thymus was reported in 12 patients: no information was available in 16 patients.

\section{Surgically excised cystic ECT}

We identified 79 cases (78 patients, 1 bilateral) of a surgically excised cystic ECT (Table 4$){ }^{4-6,12,17,18,20-28,30-36,39,40,42,49}$ The majority $(80 \%)$ of lesions were found in the neck. More than one modality of imaging was performed in $17(30 \%)$.

Pre-operative diagnoses were reported in 49 cases and none of these included an ECT as a possible diagnosis. Pre-operative diagnoses include: neuroblastoma, tuberculosis, lymphatic malformation, branchial remnant, lymphadenopathy, dermoid cyst. Eleven patients underwent a FNAC/biopsy before definitive excision: diagnosis was ECT in 3 cases, inconclusive in 1 case and incorrect in 7 cases ( 3 branchial cysts, 1 benign retention cyst, 1 infected dermoid cyst, 2 lymphadenopathies). A normal mediastinal thymus was reported in 5 patients: no information was available in 73 patients.

\section{Overall cohort and statistical analysis}

There were $101(70 \%)$ males and 24 (17\%) females; gender was not reported in 18 (13\%) patients. The average age at diagnosis was 4 years (11 days -18 years). Patients with a surgically excised cystic ECT were significantly older than patients with either a conservatively managed solid ECT or a surgically excised solid ECT $(\mathrm{p}<0.0001)$. A total of $119(79 \%)$ lesions were found in the neck: right neck $48(41.5 \%)$, left neck $66(55.5 \%)$, unspecified neck $5(4 \%)$. The median lesion volume was $19.8(0.01-1308) \mathrm{mL}$ : patients with a surgically excised cystic ECT had significantly larger lesion than patients with a conservatively managed solid ECT or a surgically excised solid ECT $(\mathrm{p}=0.0007)$. There was no difference in size between lesions located in the neck and other anatomical areas $(\mathrm{p}=0.18)$ and between right and left neck $(\mathrm{p}=0.6)$.

The presence of normal mediastinal thymus was investigated in $40(28 \%)$ patients and found to be present in $39(97.5 \%)$. For the remaining 103 patients there was no information regarding if the presence of normal mediastinal thymus was investigated. 
Overall, for the 106 ECT cases that were excised we did not find ECT as preoperative differential diagnosis in the 54 manuscripts analysed. FNAC/biopsy were performed in $25(5.6 \%)$ cases: correct diagnosis of ECT was obtained in $12(48 \%)$ cases. Regardless of the type of ECT, post-operative complications included vocal cord paresis (2), hypocalcaemia (1), seroma (1). ${ }^{4,5}, 9,68$ There were no documented reports of malignancy on histological analysis of any type of ECT. Overall follow-up which was available for 36 (25\%) patients, was 0.7 years (2 weeks -6 years).

\section{DISCUSSION}

Ectopic thymic tissue is a rare clinical entity that can occur in the neck, lung, pleura or another location in the thoracic cavity. ${ }^{78}$ Bilateral cervical ectopic thymus has also been reported. ${ }^{13}$ From our systematic review, 192 paediatric cases were identified with 150 with sufficient data to be analysed in the last 20 years. We will discuss the challenges regarding both the diagnosis and management of ECT based of the current available evidence.

\section{Presentation and Diagnosis}

ECT in children generally presents as an asymptomatic lateral neck mass. Symptoms can occur as a result of infection, ${ }^{4,}{ }^{18}$ airway obstruction, ${ }^{5,6}, 34,39$ feeding difficulties,${ }^{46,} 49$ and rarely Homer syndrome. ${ }^{50}$ We detected a significant higher incidence of lesions located in the neck $(79 \%)$ and in the male population $(79 \%)$. The lesion has also been described as an incidental finding in paediatric autopsies with an incidence as high as to $31 \% .{ }^{79}$ Rarely, ECT has been found in the autopsies of children after sudden infant death syndrome although no clear correlation has been identified with this. ${ }^{3}$ In a review of autopsies with an incidental finding of cervical ectopic tissue the ECT size demonstrated a negative correlation with age $(\mathrm{r}=-0.75 ; \mathrm{p}=$ 0.034 ) suggesting that the lesion may disappear over the first few years of life. ${ }^{44}$

The differential diagnoses in children include; congenital or acquired neck lumps such as dermoid and sebaceous cysts, thyroglossal duct cysts and branchial remnants. USS is useful in the characterisation of ECT and is now considered the first-line investigative modality. ${ }^{71}$ Sonographically, thymic tissue is identified by a homogeneous, hypoechoic mass with internal echogenicities. ${ }^{10,56,71}$ However, despite the presence of internal echoes in our case, the initial report suggested the lesion to be a branchial cleft cyst. Overall, definite diagnosis, leading to a conservative management was obtained in $30(21 \%)$ patients. For the 106 ECTs that were surgically excised, including our case, ECT was not listed as a preoperative differential diagnosis. This suggests that ECT is rarely considered in the differential diagnosis of neck masses in children. Several authors have highlighted the challenges in the pre-operative diagnosis of ECT mimicking other abnormalities such as branchial cysts, ${ }^{18,} 29,31,32,37,49$ lymphatic malformations, ${ }^{18,}$ 20, 29, 31, 77 haemangiomas, ${ }^{29}$ hamartoma, ${ }^{37}$ thyroglossal duct cysts, ${ }^{18,} 77$ teratoma,${ }^{46,}{ }^{77}$ lymphoma, ${ }^{47,}{ }^{59}$ neuroblastoma,${ }^{54}$ and dermoid cysts. ${ }^{37}$

For clinically ambiguous cases, MRI has proven to be a superior radiological modality to both characterize these lesions and document any additional ectopic thymic tissue. It also confirms the presence of continuity between the ECT and a mediastinal thymus, or the presence of a normal mediastinal thymus. ${ }^{13}$ Thymic tissue is identified by a homogeneous, isointense on T1 weighted images and hyperintense on T2 weighted images. ${ }^{56}$ The signal intensity is similar for ECT and orthotopic thymus. ${ }^{13}$

Diagnosis can also be helped by FNA or incisional biopsies. Tunkel et al. documented that FNA can accurately diagnose ECT based on presence of fibrous septa, Hassall's corpuscles, and other characteristics of normal thymic architecture. ${ }^{16}$ However, ECT has been erroneously diagnosed on FNA as lipoblastoma, ${ }^{19}$ branchial cysts $^{33,66}$ and lymph node tissue/lymphoma. ${ }^{9,33,68}$ Incisional biopsy might also be misleading and some authors have also highlighted the challenges related to histological diagnosis with incisional biopsies reported as infected/chronic inflammatory masses, vascular anomalies and lymphomas. ${ }^{8,}{ }^{15}, 47$ Similarly, in our patient the incisional biopsy documented xanthogranulomatous inflammatory change and fibrosis.

\section{Management}

Surgical excision is generally indicated in symptomatic lesions or lesions with large cystic components. However, since thymic tissue involutes with increasing age, conservative management and follow-up might 
be appropriate in cases of asymptomatic solid lesions. Notably, ECT could be the only active thymus and an absent mediastinal thymus has been documented in $50 \%$ of these patients. ${ }^{3}$ Wells et al reported that infants who are thymectomized under the age of 1 year show a significant decrease in total $\mathrm{T}$ cell counts (especially the CD2 and CD4 subsets) although they have no increase in the frequency of infections. ${ }^{80}$ Therefore, careful consideration should be taken prior to excision of an ECT in children as this might lead to potential immunoincompetence. Furthermore, thymic involution starts prior to adolescence, with a decline averaging $1 \%$ per year $^{81}$ and therefore a solid ECT could regress over time as the lesion is rarely found in adults. The most relevant findings in our systematic review is that cystic lesions are much bigger and identified at a much older age compared to solid lesions. This is secondary to the natural involution of the thymus tissue with time, and asymptomatic solid ECT could be managed conservatively. In older children, when the ECT has undergone degeneration with formation of large cysts, surgical excision might be appropriate as these will likely not have immunological function. ${ }^{57}$

One advantage of the surgical excision of an ECT is the potentially malignant transformation of this lesion. However, cervical thymoma is an extremely rare entity, with twenty cases (three malignant) currently reported in the literature, presenting at an average age of 45 years. ${ }^{18}$

Pirkey in 1954 reported a paediatric case of thymoma arising in a ECT, which was non-metastatic. ${ }^{82}$ Lewis, in a review of 32 cases of ECT documented malignant cells only in a tracheal mass of a 58 -year-old female. ${ }^{83}$ In addition, there is no data indicating that the incidence of malignant transformation of ECT is any greater than in normal thymic tissue. Furthermore, from our systematic review of the last 20 years, we did not identify any case of malignancy, suggesting that ECT is a benign lesion in children.

Finally, it is important to highlight that surgical excision of an ECT in children might have significant morbidity. As with our described case, the lesion is often adherent to surrounding structures, such as the carotid artery, the jugular vein, and/or the vagus, hypoglossal, phrenic, and recurrent laryngeal nerves. Additionally, 50\% have shown a mediastinal connection that could require a sternotomy for complete excision further supporting a conservative approach in asymptomatic lesions. ${ }^{65}$

\section{Conclusion}

We report the first systematic review on the diagnosis and management of ECT in children. ECT is a benign and relatively rare condition. We identified 192 paediatric cases in the last 20 years. However, in the vast majority of these, an ECT was rarely considered in the pre-operative differential diagnoses. General Paediatric and ENT surgeons should always include this lesion in the differential diagnosis of neck lesions children as surgical intervention might not be appropriate in a small solid lesion as this could be the only functional thymic tissue and potentially involute over time. USS should be the initial investigation of choice but in clinically ambiguous cases, an MRI scan and/or FNA should be performed before planning appropriate surgical intervention.

\section{REFERENCES}

1. Sadler TW. Langman's Medical Embryology . Wolters Kluwer, 2015.

2. Hsieh YY, Hsueh S, Hsueh C, et al. Pathological analysis of congenital cervical cysts in children: 20 years of experience at Chang Gung Memorial Hospital. Chang Gung Med J. 2003;26:107-113.

3. Ishida T, Kotani H, Miyao M, et al. Ectopic cervical thymus associated with infant death: 2 case reports and literature review.Int J Pediatr Otorhinolaryngol . 2013;77:1609-1612.

4. Billings KR, Rollins NK, Timmons C, et al. Infected neonatal cervical thymic cyst. Otolaryngol Head Neck Surg. 2000;123:651-654.

5. Hsu BS, Heatley DG and Wilhelm M. Large cervicothoracic thymic cyst causing prominent airway deviation in a 3-day-old neonate. WMJ.2011;110:185-187. 
6. Komura M, Kanamori Y, Sugiyama M, et al. A pediatric case of life-threatening airway obstruction caused by a cervicomediastinal thymic cyst. Pediatr Radiol. 2010;40:1569-1571.

7. Pai I, Hegde V, Wilson PO, et al. Ectopic thymus presenting as a subglottic mass: diagnostic and management dilemmas. Int $J$ Pediatr Otorhinolaryngol . 2005;69:573-576.

8. Schramm JC, Perry DA and Sewell RK. Retropharyngeal thymus and parathyroid gland: a case report. Int J Pediatr Otorhinolaryngol . 2014;78:163-165.

9. Statham MM, Mehta D and Willging JP. Cervical thymic remnants in children. Int J Pediatr Otorhinolaryngol . 2008;72:1807-1813.

10. Chu WC and Metreweli C. Ectopic thymic tissue in the paediatric age group. Acta Radiol. 2002;43:144146.

11. Fitoz S, Atasoy C, Turkoz E, et al. Sonographic findings in ectopic cervical thymus in an infant. J Clin Ultrasound. 2001;29:523-526.

12. Han BK, Yoon HK and Suh YL. Thymic ultrasound. II. Diagnosis of aberrant cervical thymus. Pediatr Radiol. 2001;31:480-487.

13. Tanrivermis Sayit A, Elmali M, Hashimov J, et al. Bilateral ectopic cervical thymus presenting as a neck mass: Ultrasound and magnetic resonance imaging. Pediatr Int. 2016;58:943-945.

14. Chowhan AK, Kinnera VS, Yootla M, et al. Cervical ectopic thymus masquerading as metastatic thyroid papillary carcinoma. Malays J Pathol. 2010;32:65-68.

15. Mizia-Malarz A, Sobol G, Maldyk J, et al. Cervical ectopic thymus in a 9-month-old girl: diagnostic difficulties. J Pediatr Hematol Oncol. 2009;31:599-601.

16. Tunkel DE, Erozan YS and Weir EG. Ectopic cervical thymic tissue: diagnosis by fine needle aspiration. Arch Pathol Lab Med.2001;125:278-281.

17. Cigliano B, Baltogiannis N, De Marco M, et al. Cervical thymic cysts. Pediatr Surg Int. 2007;23:12191225 .

18. Khariwala SS, Nicollas R, Triglia JM, et al. Cervical presentations of thymic anomalies in children. Int J Pediatr Otorhinolaryngol . 2004;68:909-914.

19. Ahsan F, Allison R and White J. Ectopic cervical thymus: case report and review of pathogenesis and management. J Laryngol Otol.2010;124:694-697.

20. Al-Salem AH. An unusual cervical swelling in a child. Saudi Med J. 2001;22:917-919.

21. Amanatidou V, Mavrokosta M, Kourtesis A, et al. Cervicomediastinal thymic cyst-report of a case. Thorac Cardiovasc Surg.2008;56:177-178.

22. Berenos-Riley L, Manni JJ, Coronel C, et al. Thymic cyst in the neck. Acta Otolaryngol. 2005;125:108112 .

23. Bernig T, Weigel S, Mukodzi S, et al. Ectopic cervical thymus in a 12-year-old boy: a case report. Pediatr Hematol Oncol.2000;17:713-717.

24. Betti M, Hoseini NH, Martin A, et al. Cervical thymic cyst in childhood: a case report. Fetal Pediatr Pathol. 2015;34:65-69.

25. Bhople KS, Joshi AR, Patil SP, et al. Cervical thymic cyst: a case report. Indian J Pathol Microbiol. 2007;50:585-587.

26. Bothale KA, Mahore SD, Karmarkar P, et al. IMAGES: Ectopic thymic cyst: a rare case report. Indian J Pathol Microbiol.2015;58:118-119. 
27. Cacciaguerra S, Rizzo L, Tranchina MG, et al. Ultrasound features of ectopic cervical thymus in a child. Pediatr Surg Int.1998;13:597-599.

28. Cioffi U, De Simone M, Nosotti M, et al. Horseshoe shaped ectopic cervical thymus extending into the anterior mediastinum. Eur J Surg. 2000;166:508-510.

29. Clark JJ and Johnson SM. Solid cervical ectopic thymus in an infant.J Pediatr Surg. 2009;44:e19-21.

30. Dano I, Dangoor E, Eliasher R, et al. Thymic cyst mimicking a branchial cleft cyst. J Otolaryngol. $1998 ; 27: 236-237$.

31. De Caluwe D, Ahmed M and Puri P. Cervical thymic cysts.Pediatr Surg Int. 2002;18:477-479.

32. Delbrouck C, Choufani G, Fernandez Aguilar S, et al. Cervical thymic cyst: a case report. Am J Otolaryngol. 2002;23:256-261.

33. Englender M, Kfir E and Ben-Dor D. Cervical thymic cyst: unusual age and site. Isr Med Assoc J. 2009;11:191-192.

34. Felgentreff K, Schupp W, Otten JE, et al. Inspiratory stridor and dysphagia in two newborn infants caused by ectopic thymus tissue.Eur J Pediatr. 2009;168:1141-1145.

35. Gayatri P, Sanjay D, Ajay N, et al. Mixed multilocular ectopic thymic cyst with parathyroid element presenting as neck mass. Ann Acad Med Singapore. 2012;41:271-272.

36. Hadi U, Shreif J, Soubra M, et al. Valsalva-induced cervical thymic cyst. Otolaryngol Head Neck Surg. 1997;117:S70-72.

37. He Y, Zhang ZY, Zhu HG, et al. Infant ectopic cervical thymus in submandibular region. Int J Oral Maxillofac Surg.2008;37:186-189.

38. Herman TE and Siegel MJ. Cervical ectopic thymus. J Perinatol. 2009;29:173-174.

39. Hwang TZ, Lin YJ and Tsai ST. Fourth branchial cyst presenting with neonatal respiratory distress. Ann Otol Rhinol Laryngol.2000;109:431-434.

40. Iftikhar $\mathrm{H}$ and Akhtar S. Ectopic cervical thymic cyst in a seven year old: a diagnostic challenge. $J$ Pak Med Assoc.2018;68:797-800.

41. Kacker A, April M, Markentel CB, et al. Ectopic thymus presenting as a solid submandibular neck mass in an infant: case report and review of literature. Int J Pediatr Otorhinolaryngol . 1999;49:241-245.

42. Kaufman MR, Smith S, Rothschild MA, et al. Thymopharyngeal duct cyst: an unusual variant of cervical thymic anomalies. Arch Otolaryngol Head Neck Surg. 2001;127:1357-1360.

43. Kini V, Ismail A, Aref E, et al. Ectopic Thymus: A Rare Cause of Cervical Mass in the Neonate. Pol J Radiol. 2005;70:93-95.

44. Kotani H, Ishida T, Miyao M, et al. Ectopic cervical thymus: a clinicopathological study of consecutive, unselected infant autopsies.Int J Pediatr Otorhinolaryngol . 2014;78:1917-1922.

45. Liu D, Kitajima M, Awai K, et al. Ectopic cervical thymus in an infant. Radiat Med. 2006;24:452-455.

46. Loney DA and Bauman NM. Ectopic cervical thymic masses in infants: a case report and review of the literature. Int J Pediatr Otorhinolaryngol . 1998;43:77-84.

47. Matsubayashi T, Shimizu SI, Kitazawa H, et al. Rebound enlargement of an ectopic cervical thymus mimicking relapse of lymphoblastic lymphoma. Int J Hematol. 2011;93:689-690.

48. McLean G, DeSilva A, Bergman P, et al. Solid ectopic cervical thymus in neonates with thyroid agenesis. J Ultrasound Med.2012;31:1281-1283. 
49. Meyer E, Mulwafu W, Fagan JJ, et al. Ectopic thymic tissue presenting as a neck mass in children: a report of 3 cases. Ear Nose Throat J. 2010;89:228-231.

50. Mihora LD, Jatla KK and Enzenauer RW. Homer syndrome due to ectopic cervical thymus. J Pediatr Ophthalmol Strabismus. 2006;43:46-48.

51. Millman B, Pransky S, Castillo J, 3rd, et al. Cervical thymic anomalies. Int J Pediatr Otorhinolaryngol . 1999;47:29-39.

52. Nasseri F and Eftekhari F. Ectopic thymus presenting as a right-side cervical mass in an infant. Pediatr Radiol. 2009;39:90.

53. Nawaz A, Jacobsz A and Al-Salem A. Ectopic thymus presenting as a neck swelling in a newborn. Ann Saudi Med. 1998;18:192-193.

54. Nolder AR, Agarwal A, Howard E, et al. Ectopic thymus presenting as a retropharyngeal mass: surgical approach. Ear Nose Throat J.2013;92:41-43.

55. Ozbey H, Ratschek M and Hollwarth M. Cervicomediastinal thymic cyst: report of a case. Surg Today. 2005;35:1070-1072.

56. Ozel A, Akdur PO, Celebi I, et al. Ectopic cervical thymus as a rare cause of pediatric neck mass: the role of ultrasound and MRI in the diagnosis. Case report. Med Ultrason. 2015;17:248-251.

57. Ozturk H, Karnak I, Deveci S, et al. Multilocular cervical thymic cyst: an unusual neck mass in children. Int J Pediatr Otorhinolaryngol . 2001;61:249-252.

58. Park JJ, Kim JW, Kim JP, et al. Two cases of ectopic cervical thymus: case reports and a review of the literature. Auris Nasus Larynx. 2006;33:101-105.

59. Perez-Boscollo AC, Carvalho LC, Capuci HH, et al. Thymus cyst: an option in the differential diagnosis of cervical-mediastinal tumors.Braz J Otorhinolaryngol. 2010;76:538.

60. Prabhakar G, Santhosh AN, Manjunath SS, et al. Cervical thymic cyst: a case report. Indian J Otolaryngol Head Neck Surg.2013;65:171-173.

61. Prasad KK, Gupta RK, Jain M, et al. Cervical thymic cyst: report of a case and review of the literature. Indian J Pathol Microbiol.2001;44:483-485.

62. Prasad TR, Chui CH, Ong CL, et al. Cervical ectopic thymus in an infant. Singapore Med J. 2006;47:6870.

63. Saggese D, Ceroni Compadretti G and Cartaroni C. Cervical ectopic thymus: a case report and review of the literature. Int $J$ Pediatr Otorhinolaryngol . 2002;66:77-80.

64. Sanei MH, Berjis N and Mesbah A. Cervical thymic cyst, a case report and review of the literature. $J$ Res Med Sci. 2006;11:339-342.

65. Schloegel LJ and Gottschall JA. Ectopic cervical thymus: is empiric surgical excision necessary? Int $J$ Pediatr Otorhinolaryngol . 2009;73:475-479.

66. Shenoy V, Kamath MP, Hegde MC, et al. Cervical thymic cyst: a rare differential diagnosis in lateral neck swelling. Case Rep Otolaryngol. 2013;2013:350502.

67. Srivalli M, Qaiyum HA, Srinivas Moorthy PN, et al. A case report of cervical thymic cyst and review of literature. Indian J Otolaryngol Head Neck Surg. 2011;63:93-95.

68. Sturm-O'Brien AK, Salazar JD, Byrd RH, et al. Cervical thymic anomalies-the Texas Children's Hospital experience.Laryngoscope 2009;119:1988-1993. 
69. Tandon A, Tandon R, Chandrashekhar M, et al. Cervical ectopic thymic cyst: a rare preoperative diagnosis. BMJ Case Rep. 2011;2011.

70. Thomas T, Sdrulla D and Jeyakumar A. Radiology quiz case 2. Ectopic thymus. Arch Otolaryngol Head Neck Surg. 2011;137:195-197.

71. Unal E, Duzkalir HG, Kurt-Guney S, et al. Aberrant cervical thymus and the role of ultrasonography: A case report. Turk J Pediatr.2016;58:230-231.

72. Utano K, Omoto K, Koibuchi H, et al. Case of right-neck tumor that appears to be ectopic thymus. $J$ Med Ultrason (2001).2009;36:145-148.

73. Visvanathan V, Wynne DM and Clement W. Radiology quiz case 3. Cervicomediastinal thymic cyst. Arch Otolaryngol Head Neck Surg.2011;137:719-722.

74. Wang J, Fu H, Yang H, et al. Clinical management of cervical ectopic thymus in children. J Pediatr Surg. 2011;46:33-36.

75. Zhaoqiang Z, Qingbin Z, Lei C, et al. Infant ectopic cervical thymus one case report: diagnostic and management difficulties. J Craniomaxillofac Surg. 2012;40:701-705.

76. Zielke AM, Swischuk LE and Hernandez JA. Ectopic cervical thymic tissue: can imaging obviate biopsy and surgical removal? Pediatr Radiol. 2007;37:1174-1177.

77. Hendrickson M, Azarow K, Ein S, et al. Congenital thymic cysts in children-Mostly misdiagnosed. $J$ Pediatr Surg. 1998;33:821-825.

78. Weissferdt A and Moran CA. The spectrum of ectopic thymomas. Virchows Arch. 2016;469:245-254.

79. Bieger RC and McAdams AJ. Thymic cysts. Arch Pathol.1966;82:535-541.

80. Wells WJ, Parkman R, Smogorzewska E, et al. Neonatal thymectomy: does it affect immune function? J Thorac Cardiovasc Surg. 1998;115:1041-1046.

81. Dooley J and Liston A. Molecular control over thymic involution: from cytokines and microRNA to aging and adipose tissue. Eur J Immunol. 2012;42:1073-1079.

82. Pirkey WP. Epithelioma of undescended thymus in a child. AMA Arch Otolaryngol. 1954;59:237-240.

83. Lewis MR. Persistence of the thymus in the cervical area. J Pediatr. 1962;61:887-893.

\section{FIGURES LEGEND}

Figure 1. Pre-operative ultrasound scan: reported as cystic mass with mobile internal echoes to right of midline (1A); pre-operative magnetic resonance imaging scan showing heterogenous enhancing soft tissue changes with few cystic/fluid components at right parapharyngeal space extending to retropharyngeal space (1B); histopathology showing thymic tissue with Hassall's corpuscle (arrow), H\&E (1C).

Figure 2. Preferred Reporting Items for Systematic Reviews and Meta-Analyses (PRISMA) flow diagram.

Figure 3. Total number of ectopic cervical thymus cases identified from the systematic review.

\section{Hosted file}

Ectpoic Cervical Thymus_Tables.docx available at https://authorea.com/users/314270/articles/ 444596-diagnosis-and-management-of-ectopic-solid-cervical-thymus-and-cervical-thymic-cystin-children-case-report-and-systematic-review-of-the-literature 

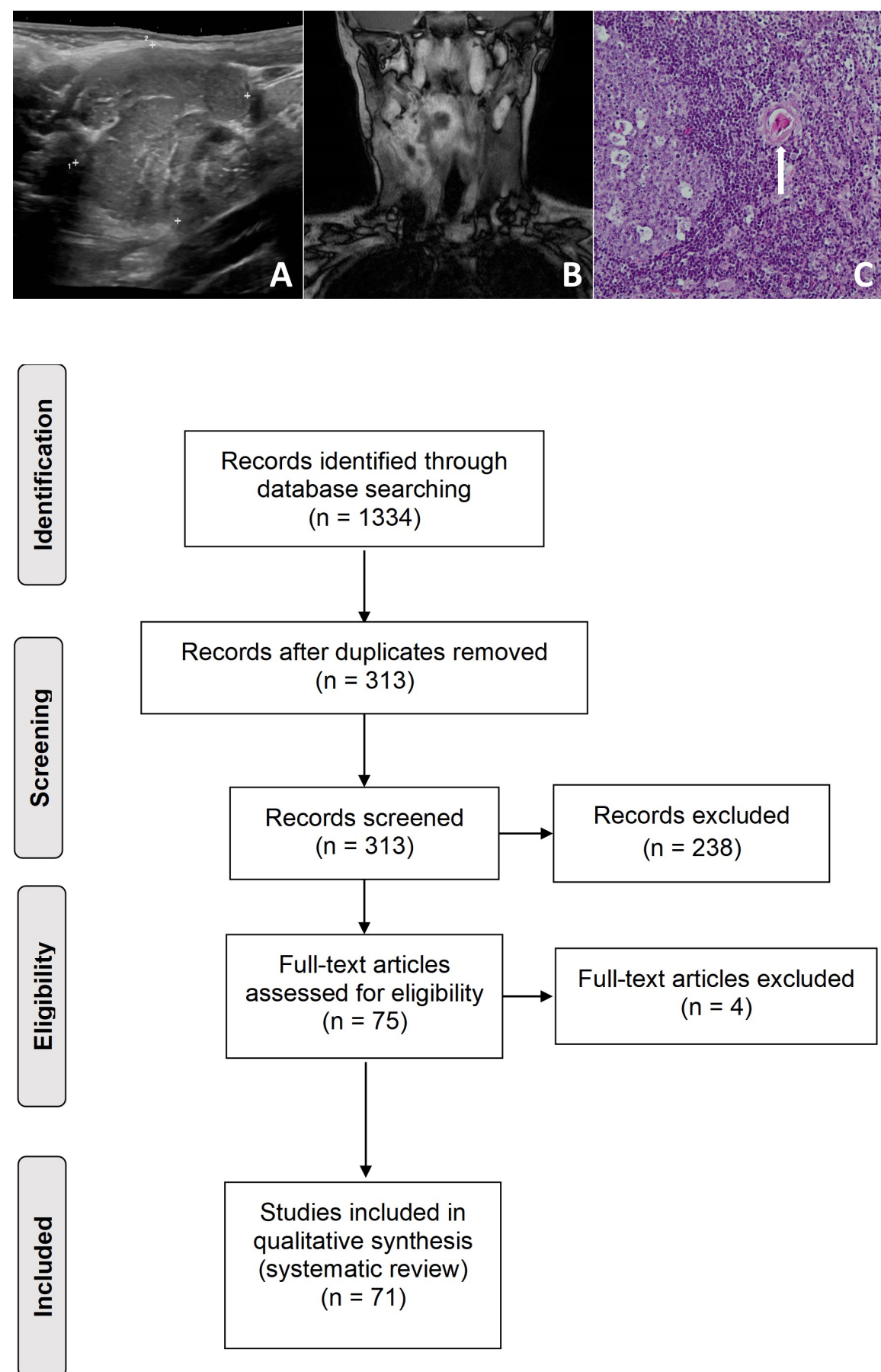


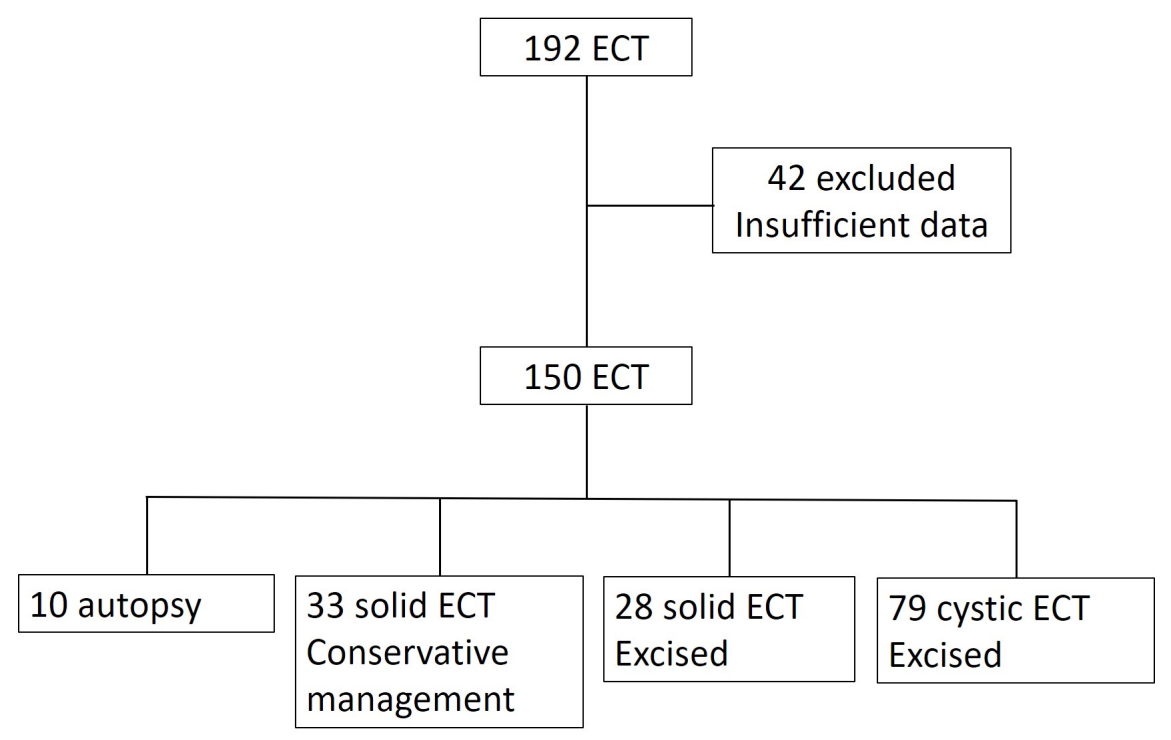

